\title{
ESTIMULAÇÃO PRECOCE EM CRIANÇAS COM SÍNDROME DE DOWN: REVISÃO BIBLIOGRÁFICA
}

\author{
EARLY STIMULATION IN CHILDREN WITH DOWN SYNDROME: \\ BIBLIOGRAPHIC REVIEW
}

\author{
Micaelle Alves Guimarães ${ }^{1}$ \\ João Eduardo Viana Guimarães²
}

RESUMO: A síndrome de Down, que se caracteriza pela presença de um cromossomo extra nas células, causa alterações físicas e psicomotoras na criança, ocorrendo um atraso no desenvolvimento global. Além de apresentar alterações físicas, a SD pode apresentar alterações no sistema respiratório, cardiopatias congênitas, alterações no sistema hematológico e gastrointestinal. Logo nos primeiros meses de vida, é importante iniciar uma estimulação para que possam adquirir um desenvolvimento melhor, e evitar o atraso. Visto que através da estimulação precoce a criança, pode alcançar movimentos, padrões e habilidade assim como as de uma criança considerada comum. A fisioterapia pode atuar com técnicas e atividades que irão estimular o desenvolvimento neuropsicomotor da criança, minimizando e prevenindo as comorbidades ao qual a síndrome de Down resulta. O estudo a seguir, tem como objetivo realizar uma abordagem das revisões bibliográficas a respeito da estimulação precoce em crianças com síndrome de Down, com enfase da atuação fisioterapêutica.

Palavras-Chave: Síndrome de Down. Criança. Estimulação precoce. Fisioterapia. Desenvolvimento neuropsicomotor.

ABSTRACT: Down syndrome, which is characterized by the presence of an extra chromosome in the cells, causes physical and psychomotor changes in children, causing a delay in overall development. In addition to presenting physical changes, DS can present changes in the respiratory system, congenital heart disease, changes in the hematological and gastrointestinal system. In the first few months of life, it is important to initiate stimulation so that they can develop better and avoid delay. Since through early stimulation the child can achieve movements, patterns and skills just like those of an

\footnotetext{
Acadêmica do Curso de Fisioterapia, Faculdade UniBrás - Unidade Rio Verde. Email: micaelle2o6@gmail.com.

2 Professor do Curso de Fisioterapia, da Faculdade UniBrás - Unidade Rio Verde. E-mail: jefisio@hotmail.com.
} 
ordinary child. Physical therapy can act with techniques and activities that will stimulate the child's neuropsychomotor development, minimizing and preventing the comorbidities to which Down syndrome results. The following study aims to approach literature reviews regarding early stimulation in children with Down syndrome, with emphasis on physical therapy.

Keywords: Down's syndrome. Kid. Early stimulation. Physiotherapy. Neuropsychomotor development.

\section{INTRODUÇÃO}

A Síndrome de Down foi reconhecida oficialmente pela Organização Mundial da Saúde (OMS), após várias denominações a partir de 1965, (SILVA e DESSEN, 2002). Segundo MARTINHO (20II) este fato foi após a descoberta da causa genética da síndrome de Down, feita por Jerônimo Lejeune $e^{3}$.

A síndrome de Down é uma condição genética, ocorrendo uma alteração do cromossomo 2i nas células do indivíduo, onde a maior parte da população possui 46 cromossomos em suas células, os indivíduos com SD possuem 47. O portador dessa condição genética pode apresentar uma série de características físicas e mentais específicas (HENN; PICCININI; GARCIAS; 2008).

O diagnóstico dessa Síndrome pode ocorrer logo após o nascimento, através da presença das suas principais características, que podem ser: hipotonia muscular generalizada, occipital achatado, pescoço curto e grosso, prega única na palma das mãos e alteração no comprimento dos membros (BARBOSA, 20II).

Logo nos primeiros meses de vida da criança portadora da SD é benéfico iniciar a estimulação precoce, pois através dela a criança possui maiores possibilidades de desenvolvimento de suas capacidades e habilidades motoras e cognitivas (HENN; PICCININI; GARCIAS; 2008).

A estimulação precoce trabalha para que desenvolva a parte neuropsicomotora da criança, objetivando evitar atrasos no seu desenvolvimento, juntamente com a intervenção

\footnotetext{
3 Foi um renomado Pediatra francês, também professor de genética e cientista, e descobridor da e seu da origem da Síndrome de Down em 1958.
} 
fisioterapêutica, sendo iniciada nos primeiros meses de vida, os resultados podem ser potencializados, promovendo melhor desenvolvimento motor, adquirindo posturas e movimentos corretos (BARBOSA, 20II).

Deve-se considerar que a Fisioterapia executa a estimulação precoce, através de protocolos a serem realizados de acordo com a necessidade de cada criança.

Frente a essas informações, o respectivo trabalho possui por objetivo maior, evidenciar a importância da estimulação precoce com a intervenção fisioterapêutica em crianças com Síndrome de Down, bem como descrever atividades e técnicas eficazes no tratamento.

Esse trabalho trata-se de uma revisão bibliográfica, de artigos publicados nas bases de dados das plataformas: Google Acadêmico, LILACS, PubMed, Biblioteca virtual em saúde e Scielo.

Os critérios de inclusão foram artigos publicados no período de 2011 a 2021 em Língua Portuguesa. Com temas relacionados a estimulação precoce em crianças com síndrome de Down.

A pesquisa foi realizada utilizando as seguintes palavras-chaves: Síndrome de Down; Criança; Estimulação precoce; Fisioterapia; Desenvolvimento neuropsicomotor.

\section{SÍNDROME DE DOWN E A ESTIMULAÇÃO PRECOCE}

A Síndrome de Down (SD) é uma alteração genética que se caracteriza pela trissomia do cromossomo 21 e em consequência apresenta o atraso no desenvolvimento motor e intelectual. A maior parte da população com SD possui a trissomia 2I, chamada simples ou livre, pois no momento da divisão a separação dos cromossomos não ocorre corretamente, resultante em um cromossomo extra nas células do indivíduo. Além da trissomia simples, possui outras diferentes formas da trissomia do cromossomo 2I, como a translocação onde os cromossomos 2i se uniram com outro cromossomo, e, o mosaicismo onde a trissomia fica presente em algumas das células (SOTORIVA; SEGURA, 2013). 
Além de apresentar as características especificas como: pescoço achatado e curto, faces achatadas, nariz em sela e pequeno, a Síndrome de Down pode apresentar alterações no sistema respiratório, cardiopatias congênitas, alterações no sistema hematológico e gastrointestinal (SOTORIVA; SEGURA, 2013).

As crianças a qual possuem a SD podem ser afetadas e ter dificuldades em suas habilidades funcionais que fazem parte do controle e programação motora (COPPEDE et.al., 2012).

Apesar dos atrasos em seu desenvolvimento, a criança com SD, pode através de estimulações aprimorar suas habilidades, ganhar um melhor desenvolvimento e qualidade de vida (SOTORIVA; SEGURA, 2013).

Segundo Bonamo e Rossetti (2002) a criança com SD, apesar de ter um atraso no seu desenvolvimento motor, pode adquirir habilidades motoras assim como as de uma criança com desenvolvimento comum, mesmo que seu aparecimento possa ser tardio sendo a uma idade superior comparado a uma criança sem atraso motor.

As crianças com Síndrome de Down fazem parte do público do serviço de estimulação precoce, pelo fato de possuir atraso no desenvolvimento global, este serviço ao qual é realizado com acompanhamento clínico de uma equipe multidisciplinar, no qual seus objetivos são minimizar e prevenir os atrasos no desenvolvimento neuropsicomotor, que irá intervir na maturação da criança e contribuir também para a orientação familiar (BRASIL, 2016a).

A estimulação precoce visa buscar o desenvolvimento e a independência no ambiente do dia a dia, escolhendo atividades de fácil compreensão e procedimento, para serem realizadas até mesmo em suas próprias residências (REGEN 1985).

Segundo BENATTI (1989) a criança precisa ser estimulada, para poder alcançar o seu desenvolvimento, assim como conhecer e tocar objetos e se socializar, dessa forma usara os seus sentidos que serão estimulados pelo movimento.

De acordo com CARSWELL (1993) através de um projeto que o mesmo realizou, tendo o objetivo crianças com Síndrome de Down a realizarem atividades básicas do seu 
dia a dia, explica como interagir a criança em seu meio, tendo também atividades para estimular o desenvolvimento motor. Tendo em vista, que a estimulação iniciada o quanto antes leva a resultados mais satisfatórios.

\section{ATUAÇÃO FISIOTERAPÊUTICA}

A Fisioterapia atuando na estimulação da criança com Síndrome de Down visa prevenir e ou minimizar as comorbidades associadas como: sequelas neurológicas, musculoesqueléticas e cardíacas (MUSTACHINI; ROZONT 1999).

A Fisioterapia possui uma atuação fundamental na estimulação da criança com Síndrome de Down, tendo em vista que a atuação é precoce sendo iniciada nos primeiros quatro meses de vida da criança, antes mesmo dos padrões anormais de posturas e movimentos surgirem (MATTOS e BELLANI, 2010).

Segundo TEIXEIRA (2006) os casos de estimulações iniciadas mais tarde, resulta

em um desenvolvimento sensório-motor com comprometimentos, podendo ter a perda de 1051 noção de espaço, percepção corporal e tendo dificuldades cognitivas.

A estimulação ocorre através de técnicas e atividades, tendo a fisioterapia convencional, realizada entre a criança e o terapeuta. Através de pesquisa os ambientes influenciam na terapia podendo ser considerada as técnicas de Equoterapia e fisioterapia aquática, como fator muito benéfico. Nos resultados da Equoterapia observa-se que a criança apresenta uma maior interação entre o terapeuta, ambiente e animal, adquirindo uma sociabilização melhor (RIBEIRO, 2007).

A Fisioterapia aquática é uma das técnicas mais utilizadas, podendo ser trabalhada com atividades lúdicas e terapêuticas, assim a criança poderá ter liberdade em seus movimentos, uma melhor correção postural, melhora do sistema respiratório e também uma sociabilização significativa, estando em um ambiente mais agradável (BASTOS, 20II). 
Segundo Rodrigues et al., (2011), a falta de rotação de tronco e consequentemente no atraso da aquisição da marcha e no equilíbrio dinâmico é consequência da hipotonia junto com a hiperfrouxidão ligamentar.

Com atuação da fisioterapia na mobilidade, incluindo a pré-marcha, dando impulso da posição ajoelhada para posição em pé, resulta em uma melhora em relação ao equilíbrio dinâmico (SILVA; KLEINHANS, 2006).

A fisioterapia possui diversos tipos de técnicas, assim incluindo também a Shantala, que trabalha juntamente com a interação da mãe e filho. A Shantala proporcionou uma melhor qualidade de vida para as crianças além de uma melhor aceitação da doença para as mães gerando um vínculo maior com os filhos. Beneficiando também no aperfeiçoamento dos movimentos das crianças, (BARBOS, et. al. 20II).

Para Janaina (2011) a Fisioterapia é uma parte essencial do desenvolvimento da criança com Síndrome de Down, aprimorando os tratamentos e transmitindo orientações aos familiares, onde atua juntamente com uma equipe multidisciplinar.

\section{CONCLUSÕES}

Compreendeu-se com base na revisão desse estudo, que há significativo acerca das características e alterações globais no desenvolvimento da criança com síndrome de Down, e que a estimulação precoce, é muito importante para o desenvolvimento neuropsicomotor, que juntamente com a atuação da fisioterapia e equipe multidisciplinar se obtém resultados positivos a criança.

É perceptível que a atuação do fisioterapeuta é essencial ao desenvolvimento da criança com SD, compreendendo que a estimulação precoce iniciada nos primeiros meses de vida trás maiores resultados e melhor desenvolvimento, visto que se tem clareza nas técnicas a serem utilizadas e transmitindo orientações aos familiares para continuidade do tratamento em casa.

Com isso, considera-se a eficácia da estimulação precoce em crianças com síndrome de Down, e a importância da atuação fisioterapêutica, contribuindo para aquisição do 
desenvolvimento motor e habilidades da criança, minimizando os impactos negativos na reabilitação e aprendizagem.

\section{BIBLIOGRAFIA}

COPPEDE, A. C et al., Atuação da fisioterapia em crianças com síndrome de down. Revista jrg de estudos académicos, Vol. IV, n. 8 p. 83, 202I

ALMEIDA. P. S. M. SCOTTA, A. P. PIMENTEL, B. M. JÚNIOR, S. B. SAMPAIO, Y. R. Incidência de lesão musculoesquelética em jogadores de futebol. Revista Brasileira de Medicina no Esporte. Brasil, v. 19, n. ${ }_{2}^{2}$, p. II2-II5, 2013.

BONAMO. L. M. M; ROSSETTI. C. B; O desenvolvimento motor em crianças com síndrome de down e a influência da família para seu aprendizado. Revista Psicologia \& Saberes, v. 9, $\mathrm{n}^{\circ} \mathrm{I6}, 2020$.

SOTORIVA, P.; SEGURA, D. C. A. Efeito da fisioterapia aquática na força muscular respiratória de crianças e adolescentes com Síndrome de Down. Arq. Cienc. Saúde UNIPAR, Umuarama, v 23, n. I, 2019.

SILVA, N. L. P; DESSEN, M.A; MARTINHO, L. S. T. A síndrome de down. Psicologia. Pt portal dos psicólogos, 2016.

BRASIL. Ministerio da Saude. Secretaria de Atenção A Saúde. A importância da estimulação precoce na microcefalia. Salão do conhecimento ciência alimentando o brasil XXIV Seminário de iniciação cientifica. 2016

GUSMÃO, Fellipe Fracho De - Educação inclusiva: a relevância da estimulação precoce para os portadores da Síndrome de Down. CSO - trabalhos de conclusão de curso Niterói: 150. P. 9 a 10. 2015

CARSWELL, W. A. Importância da estimulação precoce em bebes portadores de síndrome de down. Revisão de literatura. Ver. Bras. Terap. E saúde, Curitiba, v. i p. 54-56, 2010

MATTOS. B; BELLANI, F. A importância da fisioterapia na intervenção precoce em crianças com síndrome de down. Revisão de literatura. Universidade Fernando pessoa FCS/ESS licenciatura em fisioterapia projeto e estagio profissionalizante II. 2020 
TEIXEIRA. L, JANAINA. H., et al. Significado e vivencias de pais de crianças com síndrome de down que realizam fisioterapia. Centro universitário Leão Sampaio. 2018 